\section{Cancer presentation patterns in Lagos, Nigeria: Experience from a private cancer center}

\author{
Abimbola Fapohunda, ${ }^{1}$ \\ Adeola Fakolade, ${ }^{2}$ Jesutofunmi Omiye, ${ }^{3}$ \\ Oluwasegun Afolaranmi, ${ }^{3}$ \\ Oreoluwa Arowojolu, ${ }^{3}$ \\ Tunde Oyebamiji, ${ }^{3}$ \\ Chukwumere Nwogu, ${ }^{4}$ \\ Alexander Olawaiye, ${ }^{5}$ Jimoh Mutiu ${ }^{4}$ \\ ${ }^{1}$ University of Pittsburgh, PA, USA; \\ ${ }^{2}$ Ashtabula County Medical Center, \\ Ashtabula, OH, USA; ${ }^{3}$ College of \\ Medicine, University of Ibadan, Nigeria; \\ ${ }^{4}$ Lakeshore Cancer Center, Lagos, \\ Nigeria; 'Magee-Women's Hospital of \\ UPMC, Pittsburgh, USA
}

\begin{abstract}
Background: Cancer incidence and mortality is increasing worldwide. In 2018, there were an estimated 18.1 million new cancer cases and 9.6 million cancer deaths. In Nigeria, it is estimated that 100,000 new cases occur annually, with a high case fatality ratio. The burden of cancer in Nigeria is significant, as the country still grapples with infectious diseases and has limited data on cancer epidemiology. Our study is descriptive using data from a hospital-based regi-
\end{abstract} stry.

Objectives: This retrospective study assesses the characteristics of patients that presented to a private cancer center in Lagos, Nigeria. We aimed to update knowledge on the current trends of cancer in Nigeria as exemplified by the experience of this cancer center and set a foundation for guiding future research and policy efforts in cancer screening, prevention, and control.

Methods: The records of all the 548 oncology patients registered at the Lakeshore Cancer Center (LCC) cancer registry from January 2015 to June 2018 were reviewed for this study.

Results: Most common cancer types were breast cancer for females $(46 \%)$ and prostate cancer for males (32\%). $92 \%$ of the tumors were malignant and $97 \%$ of the patients were symptomatic. Among patients diagnosed with cancer, $49 \%$ were $\leq 50$ years old, $90 \%$ paid for their healthcare out of pocket, and $67 \%$ did not complete treatment.

Conclusions: This study highlights the state of cancer care in Nigeria and should guide future research, with a focus on public awareness, screening programs and implementation of novel cancer control policies and infrastructure that supports early detection.

\section{Introduction}

An estimated 18.1 million new cancer cases occurred in 2018 worldwide, according to the International Agency for Research on Cancer (IARC), using the GLOBOCAN 2018 estimates of cancer incidence and mortality. ${ }^{1,2}$ In the same year, an estimated 9.6 million people died from cancer-related causes, and approximately $70 \%$ of these deaths occurred in low- and middle-income countries (LMICs). ${ }^{1,2}$ In 2018, across both sexes, the commonest new cancers worldwide in descending order were lung with approximately 2.1 million (11.6\% of the total cases and $18.4 \%$ of the total cancer deaths), breast with approximately 2.1 million $(11.6 \%$ of the total cases and $6.6 \%$ of the total cancer deaths), prostate with approximately 1.27 million cases (7.1\% of total cases and $3.8 \%$ of cancer deaths), colorectal with approximately 1.09 million $(6.1 \%$ of cases and $5.8 \%$ of deaths $)$, and non-melanoma skin cancer with approximately 1.04 million $(5.8 \%$ of cases and $0.7 \%$ of deaths). ${ }^{1}$ In 2018 , males saw a higher incidence of cancers with 9.5 million new cases compared to 8.6 million new cases in females. ${ }^{1}$ In males, the top 5 cancers accounted for over $50 \%$ of new cancers and include cancers of the lung (14.5\%), prostate $(13.5 \%)$, colorectal $(10.9 \%)$, stomach $(7.2 \%)$, and liver $(6.3 \%) .{ }^{1}$ In females, the corresponding top 5 cancers were breast $(24.2 \%)$, colorectal $(9.5 \%)$, lung $(8.4 \%)$, cervical $(6.6 \%)$, and thyroid $(5.1 \%) .{ }^{1}$ The rising incidence of cancer has been attributed to population growth and aging population and adoption of behavioral and lifestyle factors such as tobacco use, alcohol intake, unhealthy diet, and physical inactivity. ${ }^{3-6}$

In Nigeria, some 100,000 new cancer cases occur every year, with a high case fatality ratio. ${ }^{7,8}$ Studies of cancer epidemiological patterns from cancer registries show that the most frequent cancers among Nigerian men are prostate and colorectal, while breast and cervical cancers are the commonest in women, ${ }^{9}$ in contrast to worldwide figures listed earlier. With approximately $20 \%$ of the population of Africa, Nigeria contributed $15 \%$ to the estimated 681,000 new cases of cancer that occurred in the continent in 2008. ${ }^{10}$ The burden of cancer in Nigeria is significant, as the country still grapples with infectious diseases with limited data on cancer epidemiology. Also, programs directed at cancer screening, early detection, primary prevention policies and standardized cancer treat-
Correspondence: Abimbola Fapohunda, University of Pittsburgh, Pittsburgh, PA PA 15260, USA

Tel.: +1.412.303-2024.

E-mail: aof3@pitt.edu

Key words: Cancer center, cancer epidemiology, Cancer registry, Nigeria.

Acknowledgements: We would like to thank the clinical team and consultant oncologists for providing the opportunity to conduct the research at Lakeshore Cancer Center, Lagos, Nigeria.

Contributions: All the authors contributed to the conception of the work, acquisition, analysis, and interpretation of data for the work. They also contributed to the initial manuscript draft, critical revision for important intellectual content and final approval of the version to be published. Drs. Nwogu, Olawaiye and Jimoh contributed to critical revision for important intellectual content and final approval of the version to be published.

Conflict of interest: The authors declare no potential conflict of interest.

Funding: None.

Ethical approval: Institutional Review Board (IRB) approval was obtained from the University of Pittsburgh.

Received for publication: 18 June 2019

Revision received: 2 January 2021.

Accepted for publication: 2 January 2021.

This work is licensed under a Creative Commons Attribution NonCommercial 4.0 License (CC BY-NC 4.0).

(C) Copyright: the Author(s),2020

Licensee PAGEPress, Italy

Journal of Public Health in Africa 2020; 11:1138 doi:10.4081/jphia.2020.1138

ment are almost non-existent. ${ }^{11}$ This is a result of the general inadequacies of the healthcare system in Nigeria. In 2017, Nigeria spent only $3.7 \%$ of her Gross Domestic Product (GDP) on healthcare, ${ }^{12,13}$ and increased public healthcare spending has been associated with better health outcomes. ${ }^{14-16}$ In 2010, the World Health Organization ranked Nigeria's healthcare system 187 out of 191 countries. ${ }^{17}$ There is a lack of universal health coverage, and it is estimated that $<5 \%$ of the population is covered by some form of health insurance, and the majority of patients have high out of pocket payments. ${ }^{18}$ Out of pocket payments account for over $70 \%$ of total healthcare expenditures in Nigeria; in 2017, the per- 
centage estimated by the World Bank is $77 \%{ }^{18,19}$ This cuts across every form of healthcare including oncological care. Beyond this, Nigeria has limited health infrastructure to deal with the rising burden of cancers. ${ }^{20}$ In Nigeria, like many other low- and middle-income countries (LMIC), allocation of public funds to cancer care is low, making the case for public-private partnerships including a dedicated oncology center, one that is well funded and focused on the holistic need of cancer patients. ${ }^{21}$

Lakeshore Cancer Center (LCC) is the first operational facility in Nigeria solely dedicated to cancer prevention and treatment. LCC was launched on January 24, 2015, it is located in Lagos, the most populous city in Africa where 22 million people live according to 2016 demographic data, and is closely affiliated with the oldest cancer center in the world, the Roswell Park Cancer Institute (RPCI), Buffalo, New York, USA. The team at LCC consists of certified cancer specialists and a cross-section of passionate and highly dedicated professionals. Through collaboration between local experts who offer an in-depth knowledge of the peculiarities of the Nigerian healthcare culture, and international oncology consultants, LCC provides a comprehensive range of services covering a broad spectrum of cancers. The LCC also has a hospital-based cancer registry, established in July, 2017, and is affiliated with the Nigerian National System of Cancer Registries (NSCR), the supervisory body of cancer registries in Nigeria. There are currently 13 Population Based Cancer Registries (PBCRs) and 20 Hospital Based Cancer Registries (HBCRs) in Nigeria, which includes LCC's registry. 22

This study was conducted to determine the pattern and distribution of cancers and characteristics of oncology patients that were presented to the only designated private comprehensive cancer care center in Lagos, Nigeria. It aims to provide updated knowledge on the current trends of cancer presentation in Nigeria and to set a foundation for guiding future research and policy efforts in comprehensive cancer control.

\section{Materials and Methods}

\section{Study design}

This is a retrospective and descriptive cross-sectional study of oncology patients at Lakeshore Cancer Center (LCC) from January 2015 to June 2018. This study was approved by the University of Pittsburgh Institutional Review Board (IRB) (\#PRO18050101). Patient information was de-identified prior to giving the Principal
Investigator (PI) access to the data for review and analysis. The data extracted from the LCC registry for analyses was on patient's socio-demographic characteristics (age, gender, marital status, occupation, education, religion, and ethnicity) and lifestyle behaviors (smoking \& alcohol consumption). Ethnicity data is reported as part of demographic data collected. Family history of cancer was examined and type of health care coverage was gathered to determine patients that paid out of pocket or are covered by Health Maintenance Organizations (HMOs). The basis of diagnosis, presence of symptoms, tumor behavior, types of treatment and patients that completed treatment were collected to determine the overall patient's clinical profiles and outcomes. Chronic disease risk factors were assessed by collecting data on HIV, asthma, hypertension, diabetes and peptic ulcer disease to determine comorbidities. Other factors examined in the study were the use of traditional medicine prior to visiting the clinic, patient awareness of LCC, and any previous healthcare contact to determine if patients were newly diagnosed or for follow-up care.

\section{Study participants and sample size}

Of the 663 patients that visited LCC from January 2015 to June 2018, 17\% (115) of them sought other healthcare services such as cancer screening, chronic disease management, and cancer education, while the remaining 548 are oncology patients. All the 548 oncology patients registered in the LCC cancer registry from January 2015 to June 2018 were recruited for the study. LCC's cancer registry was established in July 2017 and patients managed in the center prior to the establishment of the cancer registry were retrospectively registered.

\section{Data analysis}

Data was analyzed using the IBM Statistical Package for Social Sciences (SPSS) version 25.0, produced by IBM Corp. Released 2017. IBM SPSS Statistics for Windows, Version 25.0. Armonk, NY: IBM Corp. Variables were analyzed using descriptive statistics.

\section{Results}

Socio-demographic and clinical data of 548 patients who were registered at LCC cancer registry from January 2015 to June 2018 were analyzed. The demographic characteristics of oncology patients treated at the center were $73 \%$ female, $74 \%$ married, $87 \%$ had a tertiary level of education and $81 \%$ were professionals and business owners. The average age of the patients was 52 years old and 49\% (269) of the patients diagnosed with cancer were 50 years old or less. Patients were mostly Christians (91\%) and predominantly from the Yoruba and Igbo (76\%) ethnic groups (Table 1).

Breast cancer was the most common cancer in women with 181 cases (46\%), while the commonest cancer in men was prostate cancer with 50 cases (32\%) (Figure 1). Overall, the majority of cancer diagnoses were: breast (33\%), gynecological cancers $(14 \%)$, prostate $(9 \%)$ and colorectal (7\%) (Table 2).

A review of health behaviors shows that $26 \%$ of the patients consumed alcohol and $6 \%$ smoked. Only $21 \%$ of the patients had a family history of cancer. The most common chronic disease patients reported was hypertension $(31 \%)$, while $16 \%$ had other comorbid diseases. An overwhelming majority $(90 \%)$ of the patients were private (nonHealth Maintenance Organization-HMO) and paid for their healthcare out of pocket.

Table 1. Socio-demographic characteristics of oncology patients.

\begin{tabular}{lc}
\hline Variables & $\mathbf{N}(\%)$ \\
Age, (Mean 52 years) & 548 \\
<20 years & $3(<1)$ \\
21-30 years & $33(6)$ \\
31-40 years & $110(20)$ \\
41-50 years & $123(22)$ \\
$51-60$ years & $125(23)$ \\
$\geq 60$ years & $154(28)$ \\
Gender & 548 \\
Female & $401(73)$ \\
Male & $147(27)$ \\
\hline Marital Status & 548 \\
Married & $402(74)$ \\
Single & $51(9)$ \\
Widowed & $56(10)$ \\
Divorced/Separated & $36(7)$ \\
Occupation & $413^{*}$ \\
Professionals/Administrators & $255(62)$ \\
Business Owners & $78(19)$ \\
Retirees & $67(16)$ \\
Unemployed & $4(1)$ \\
Student & $9(2)$ \\
\hline Religion & $521^{*}$ \\
Christian & $475(91)$ \\
Muslim & $45(8)$ \\
Hindu & $1(1)$ \\
Ethnicity/Tribe & 548 \\
Yoruba & $227(41)$ \\
Igbo & $192(35)$ \\
Edo & $12(2)$ \\
Other & $117(22)$ \\
\hline Education & $328^{*}$ \\
Primary & $10(3)$ \\
Secondary & $33(10)$ \\
Tertiary & $284(87)$ \\
\hline *some missing data. & \\
&
\end{tabular}


Only $9 \%$ of the patients revealed using traditional medicine prior to their visits to the clinic. Thirty-nine percent of the patients were referred by their doctors or other hospitals while $20 \%$ found the center online. Forty percent of the patients had previous contact with other healthcare systems abroad and $45 \%$ had previous contact with domestic private or teaching hospitals before referral to LCC. Definitive diagnosis was made with histology of the primary site in $95 \%$ of cases, while cytology techniques were diagnostic in $5 \%$ of the cases (Table 4). Table 4 shows that of the 547 cases for which we had data on symptoms at diagnosis, $97 \%$ of the patients were already symptomatic with symptoms ranging from local to systemic, depending on the tumor site. 546 patients had a diagnosis that was either clinical, histology or cytology based. Of the 545 patients whose tumor behavior was reported, $92 \%$ of the tumor was malignant, $5 \%$ in situ, $1 \%$ benign and $2 \%$ uncertain. Of the 436 patients that had TNM staging available, nearly half (49\%) of them were Stage IV disease, $26 \%$ were Stage III, $17 \%$ were stage II and $8 \%$ Stage I cancer. Over a third of the patients $(39 \%)$ received single treatment modalities which included: chemotherapy $(18 \%)$, surgery $(16 \%)$, radiotherapy (1\%), hormonal therapy (1\%), immunotherapy $(2 \%)$, and targeted therapy $(1 \%)$. Most patients $(61 \%)$ received a combination of the above modalities and $61 \%$ of treated patients received a combination of at least two treatment modalities in various forms while a few benefited from up to four modalities.

Table 5 shows available follow-up and outcome information from January 2015 to June 2018. The follow-up data consists of all patients $(n=663)$ including those who sought care for non-cancer treatment reasons were included, highlighting one of the challenges of cancer registration in Nigeriadata storage is inconsistent. Nine percent were active patients, $13 \%$ were receiving follow-up care, $40 \%$ were lost to follow-up and $38 \%$ are deceased. Table 5 also shows that only $21 \%$ of the oncology patients completed treatments, $12 \%$ are currently undergoing treatments (active and followup care) and $67 \%$ did not complete treatment.

\section{Discussion}

In this study, we reviewed cancer presentations patterns at a private cancer care facility in Lagos, Nigeria. We aimed to provide some knowledge on presentation patterns in Lagos, Nigeria. Our results show a high preponderance of late stage cancer pre-

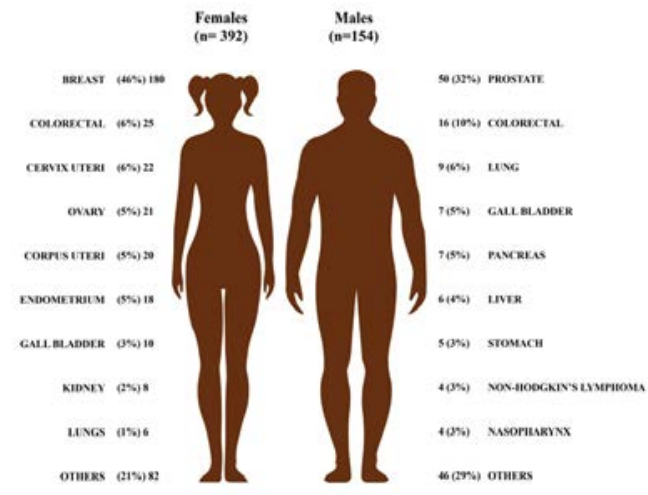

Figure 1. Cancer site by frequency based on gender.

Table 2. Cancer site by gender and overall frequency.

Site Female Gender Male Total, n (\%)

Central nervous system

$\begin{array}{llll}\text { Brain } & 2 & 1 & 3(<1) \\ \text { Meninges } & 0 & 1 & 1(<1)\end{array}$

$180-1181(33)$

Respiratory system

$\begin{array}{ll}\text { Nose } & 1 \\ \text { Accessory Sinuses } & 1 \\ \text { Nasopharynx } & 1 \\ \text { Lung } & 6\end{array}$

\begin{tabular}{cc}
2 & $3(<1)$ \\
2 & $3(<1)$ \\
4 & $5(1)$ \\
9 & $15(3)$ \\
\hline
\end{tabular}

Lustrointestinal system

Tongue

Parotid

Oropharynx

Hypopharynx

Esophagus

Tonsil

Stomach

Small intestine

Colorectal

Anus

Liver

Gallbladder and bile tract

Pancreas

Peritoneum

Gynecological

Cervix uteri

Corpus uteri

Ovary

Vagina

Endometrium

\section{1}

ale reproductive tract

ale reproductive tract
Prostate

Testis

Scrotum

Urinary System

$$
\text { Kidney }
$$

Hematological

Hodgkin's Lymphoma

Non-Hodgkin's Lymphoma

Leukemia

Multiple myeloma

Plasmacytoma

Bone

\section{Endocrine}

Thyroid

Others/unspecified

Total

*Some missing data.
1
0
1

0

3

3
0

0
4

4
3

3
25

25
5

5

5
10

10

5
0

$2(<1)$

$1(<1)$

$1(<1)$

$2(<1)$

5 (1)

$1(<1)$

9 (2)

6 (1)

41 (7)

5 (1)

11 (2)

17 (3)

12 (2)

$1(<1)$

\begin{tabular}{ccc}
22 & - & $22(4)$ \\
20 & - & $20(3)$ \\
21 & - & $21(4)$ \\
1 & - & $1(<1)$ \\
18 & - & $18(3)$ \\
\hline
\end{tabular}

$1(<1)$

$1(<1)$ 9 (2)

$3(<1)$

5 (1)

$3(<1)$

$3(<1)$

$2(<1)$

5 (1)

$2(<1)$ $48(9)$ $546(100)$ 
sentation, and the most prevalent cancers across both sexes is breast cancer. In females, the most common cancer is breast while in males, we found the most common cancer to be prostate cancer. Epidemiology of cancer is known to vary across different regions of the world. ${ }^{1}$ Trends in cancer incidence across populations, gender and age are important in defining policy, scientific research, and cancer interventions. Such data assist us to better guide allocation of resources in the fight against cancer. In a country like Nigeria, where there is paucity of studies with accurate documentation of cancer trends, our study offers a snapshot of an important problem in Nigeria. In this retrospective, descriptive cross-sectional study of a Nigerian hospital-based cancer registry, we reviewed the patterns and presentations of cancers at the Lakeshore Cancer Center (LCC).

Oncology care in Nigeria is constrained, and has limited capacity. ${ }^{21}$ In total, Nigeria has 9 designated comprehensive cancer care centers, 8 public and 1 private, which is the LCC. ${ }^{23}$ In 2018, it was estimated that there were 26 oncologists in Nigeria, compared to 11,700 in the United States. ${ }^{24}$ With the limited access to quality cancer care, LCC, as a designated comprehensive cancer care center plays an important role in cancer prevention and treatment. LCC also contributes to knowledge on the current cancer trends in Nigeria and sets a foundation on which to build future research and policy efforts in cancer control. In Nigeria, the resourceconstrained health care system, lack of cancer awareness, poverty, shortage of welltrained health care personnel and inadequate research infrastructure all contribute to adverse cancer outcomes. ${ }^{25-28}$ Furthermore, for many patients, healthcare practitioners are a last resort in addressing health concerns, ${ }^{29-31}$ contributing to late-stage diagnosis and poor cancer outcomes.

It is well known that advancing age is the most important risk factor for the development of cancer. ${ }^{32,33}$ We had similar findings in our study, the median age for all cancers was 52 years. When compared to data from high income countries, cancers are diagnosed at older ages. In the United States, the median age of cancer diagnosis in men and women is 66 years, and $25 \%$ of new cancer cases are diagnosed in people aged 65-74 years. ${ }^{32}$ In our study, cancer prevalence was highest in the 41-60-year-old age bracket, with $45 \%$ of all diagnosed cancers. Overall, $49 \%$ of cancer cases in our study were diagnosed in patients aged 50 years old or younger, showing a skew towards a younger demographic, and makes a case for early cancer prevention programs.
Table 3. Lifestyle, family history, referrals, and chronic disease characteristics of oncology patients.

\begin{tabular}{cc}
\hline Variables & N $(\%)$ \\
Lifestyle & Alcohol $539^{*}$; Smoking $540^{*}$ \\
Alcohol consumption & $138(26)$ \\
Smoking & $31(6)$ \\
Family history & 548 \\
Yes & $116(21)$ \\
No & $432(79)$ \\
\hline Type of patient & 548 \\
Private & $493(90)$ \\
HMO/Company & $55(10)$ \\
Chronic diseases & 548 \\
Comorbidities** & $90(16)$ \\
HIV & $6(1)$ \\
Asthma & $17(3)$ \\
Hypertension & $172(31)$ \\
Diabetes & $54(10)$ \\
Peptic ulcer & $50(9)$ \\
No chronic diseases & $159(29)$ \\
\hline Traditional medicine & $547 *$ \\
Yes & $47(9)$ \\
How patient found lakeshore & 548 \\
Online & $110(20)$ \\
Doctor/Hospital & $212(39)$ \\
Relatives & $108(18)$ \\
Other & $118(22)$ \\
\hline Previous healthcare contact & $257^{*}$ \\
Abroad & $104(40)$ \\
Domestic & $116(45)$ \\
Unspecified & $37(15)$ \\
\hline
\end{tabular}

*some missing data; **>1 chronic illness.

Table 4. Clinical outcomes of oncology patients at Lakeshore cancer center.

\begin{tabular}{|c|c|c|c|}
\hline Variables & N (\%) & Variable & N $(\%)$ \\
\hline $\begin{array}{l}\text { Basis of diagnosis } \\
\text { Histology of primary } \\
\text { Cytology } \\
\text { Clinical only }\end{array}$ & $\begin{array}{c}546^{*} \\
516(94) \\
26(5) \\
4(1)\end{array}$ & $\begin{array}{l}\text { Patients } \\
\text { Active } \\
\text { Follow-up } \\
\text { Lost to Follow-up }\end{array}$ & $\begin{array}{c}663^{* *} \\
59(9) \\
87(13) \\
265(40)\end{array}$ \\
\hline $\begin{array}{l}\text { Presence of symptoms } \\
\text { Symptomatic } \\
\text { Asymptomatic }\end{array}$ & $\begin{array}{c}547^{*} \\
531(97) \\
16(3)\end{array}$ & $\begin{array}{l}\text { Deceased } \\
\text { Complete treatment } \\
\text { Yes }\end{array}$ & $\begin{array}{c}252(38) \\
539 * \\
113(21)\end{array}$ \\
\hline $\begin{array}{l}\text { Behavior of tumor } \\
\text { Benign }\end{array}$ & $\begin{array}{l}545^{*} \\
4(1)\end{array}$ & $\begin{array}{l}\text { No } \\
\text { Ongoing } \\
\end{array}$ & $\begin{array}{l}361(67) \\
65(12)\end{array}$ \\
\hline $\begin{array}{l}\text { In Situ } \\
\text { Malignant } \\
\text { Uncertain }\end{array}$ & $\begin{array}{c}27(5) \\
504(92) \\
10(2)\end{array}$ & $\begin{array}{l}{ }^{*} \text { some missing data, }{ }^{* *} \text { con } \\
\text { patients and those that soug } \\
\text { cancer screening, chronic dis } \\
\text { tion. }\end{array}$ & $\begin{array}{l}\text { me data for } \\
\text { hcare service } \\
\text { ent, and can }\end{array}$ \\
\hline
\end{tabular}

In Situ $27(5)$

Malignant $\quad 504(92)$

Uncertain $10(2)$

$\begin{array}{cc}\text { Staging } & 436^{*} \\ \text { I } & 35(8) \\ \text { II } & 75(17) \\ \text { III } & 112(26) \\ \text { IV } & 214(49)\end{array}$

patients and those that sought other healthcare services oncology cancer screening, chronic disease management, and cancer education.

Table 5. Patient outcomes from January 2015 to June 2018.

\begin{tabular}{lc}
\hline Type of treatment & $406^{*}$ \\
Single therapy & \\
Chemotherapy & $76(19)$ \\
Surgery & $65(16)$ \\
Radiotherapy & $5(1)$ \\
Hormonal & $9(2)$ \\
Combination therapy & \\
Chemotherapy & $144(35)$ \\
Surgery & $91(22)$ \\
Radiotherapy & $9(2)$ \\
Hormonal & $7(2)$ \\
\hline *Some missing data. &
\end{tabular}


Nigeria has a young population with a median age of 17.9 years and a current life expectancy of 55.2 years. ${ }^{34}$ As life expectancy improves and the population lives to older ages, the skew may disappear.

Across both genders, the prevalence of cancer was 2.3 times higher in females compared to males, $73 \%$ vs $27 \%$ respectively. This finding is in opposition to findings reported by a paper examining cancer registry trends in southwest Nigeria that showed a male preponderance of $64.5 \%$ of total cancers. ${ }^{35}$ However, data from other cancer registries in Lagos State show numbers and trends similar to ours, with the registries in Lagos University Teaching Hospital (LUTH) and Lagos State University Teaching Hospital (LASUTH) showing percent female prevalence of $73.5 \%$ and $74.9 \%$ respectively. ${ }^{36}$ In our study, breast cancer was the commonest cancer overall $(33 \%)$, and other gynecological cancers (cervix uteri, corpus uteri, vaginal, endometrial and ovarian cancers accounting for an additional $14 \%$ approximately. The higher female prevalence may also be explained by the differences in health seeking behaviors in both genders. Available data suggests that females are more likely to seek health care compared to males. ${ }^{37}$

In our study, the commonest type of cancer overall was breast cancer $(33.0 \%)$, followed by prostate cancer $9 \%$, colorectal cancer $7 \%$, cervical cancer $4 \%$ and ovarian cancer $4 \%$. We also noted a high percentage of unspecified cancers (9\%). Lung cancer which is the commonest worldwide ranks $9^{\text {th }}$ overall in our study. Our data shows colorectal cancer ranking second and cervical cancer ranking third. Cervical cancer is a highly preventable disease, and through aggressive HPV vaccination and cervical cancer prevention programs, is set to be eliminated in Australia in the coming years. ${ }^{38}$ As cervical cancer awareness, prevention and screening modalities become ubiquitous, other gynecological cancers and colorectal are poised to take center stage. Since the introduction of the HPV vaccine into the country and the vaccine becomes more accessible, we anticipate that in the future cervical cancer incidence will continue to decrease.

In males, the patterns we found were similar in some aspects to data reported from other registries. In our study, prostate cancer was the commonest cancer, accounting for $32 \%$ of all cancer cases, followed by colorectal cancer at $10.0 \%$. A unique finding in our data is that lung cancer ranked third amongst all male cancers at $7.6 \%$. In previous studies in Nigeria registries, lung cancer was not among the top 5 commonly occurring cancers in men. ${ }^{36}$
The stage of cancer at presentation is an important contributor to the mortality and outcome of cancer treatment. Cancer care in Nigeria is characterized by late stage presentation after first symptom and delayed diagnosis. ${ }^{39,40}$ This was also true in our study as we found that $75 \%$ of patients presented late (Stage 3 and 4). As a descriptive study, we were unable to explore the reasons for delayed presentation and where patients typically visit prior to presenting to LCC. We recommend further studies to explore these important questions.

In our study, $97 \%$ presented with symptoms, which can be an indication of advanced disease. ${ }^{41}$ In Nigeria, routine cancer screening programs are largely unavailable, ${ }^{42}$ and there are various myths that surround cancer especially as it relates to prevention and treatment. ${ }^{43,44}$ All of the above factors are probable reasons for these findings. We recommend that cancer awareness and screening need to take a more aggressive form in Nigeria as symptomatic presentation also increases cancer-related morbidity and mortality. $40 \%$ of patients in the study were 'lost to follow-up' and only $21 \%$ completed treatments. The exorbitant costs of cancer care are unaffordable to many Nigerians, and this may result along with other factors in many patients cutting short their treatment plans or avoiding treatment altogether. ${ }^{26}$

In Nigeria, as noted earlier, health insurance coverage for cancer prevention and treatment is rare. ${ }^{16,19}$ The lack of structured access and health infrastructure lead many individuals to delay treatment until they are symptomatic. Our results revealed a highly educated group, and an overwhelming majority of the patients were private (nonHealth Maintenance Organization-HMO) and paid for their healthcare out of pocket. With the majority of the patients in our study being 'highly' educated, an indicator of elevated socioeconomic status, patients in our study were better positioned than most to afford care. However, many reported delays to treatment and/or incomplete treatment. Public healthcare financing is limited- as noted earlier, $77 \%$ of healthcare spending is out of pocket. Nigeria's middle class, approximately $23 \%$ of the population earns between $\$ 480$ and $\$ 645$ monthly, ${ }^{45}$ and the minimum monthly wage is NGN30, 000 or $\$ 77.32 .{ }^{46}$ Over $40 \%$ of Nigerians live below the poverty line. ${ }^{47}$ With these numbers, it is no surprise that cost is a major issue in seeking cancer care in Nigeria and can be prohibitive to patients. ${ }^{48}$

Nearly half of the patients had previous contact with other healthcare systems abroad, this is a common practice with Nigerians who can afford the cost of treat- ment overseas. ${ }^{49}$ The majority of the population does not have the luxury to access treatment abroad or have access to quality cancer care at a domestic private or teaching hospital. It is not unusual for families of individuals diagnosed with cancer to exhaust all of their life savings to pay for the cost of their treatment. ${ }^{50}$

The pluralistic system that includes standard, alternative and traditional health care delivery systems in Nigeria, all operating alongside one another may contribute to delayed treatments. ${ }^{51,52}$ Many people seek pastoral care because they can't afford the cost of conventional therapy. Spiritual healing seems to be an alternative that many Nigerians use to address some of their health needs. ${ }^{53}$ People realize that there are limited options regarding access to cancer care, and many feel more inclined to seek pastoral care when they receive negative diagnoses.

\section{Study limitations}

Our study was based on data solely derived from a single hospital-based cancer registry. Thus, it might not provide an accurate picture of the patterns in the general population. Our data is also derived from a private health care facility where most of the patients are of higher SES, and not reflective of the majority of the country. We were unable to provide mortality data as this was not captured in the cancer registry. The relatively small sample size and retrospective nature of our study are also limitations to this study and we recommend further studies to effectively document cancer trends in Nigeria. Due to the challenges of cancer registration, not all patients in the registry had data for each variable examined, therefore, we had some missing variable data for some patients.

\section{Conclusions}

This study highlights some of the problems in cancer care in Nigeria. Breast and prostate cancer were two of the most common cancers seen at this center and the majority of patients had advanced stage disease on initial presentation. The low rate of treatment completion may be related to affordability, thus emphasizing the need for healthcare financing innovations. Data such as those presented here should guide future research and policy directed toward comprehensive cancer control with a focus on public awareness and screening programs. There is an urgent need to strengthen public and private institutions, in the areas of research, patient care, and implementation of novel cancer control policies. 


\section{References}

1. Bray F, Ferlay J, Soerjomataram I, et al. Global cancer statistics 2018: GLOBOCAN estimates of incidence and mortality worldwide for 36 cancers in 185 countries. Cancer J Clin 2018;68:394424.

2. World Health Organization. Cancer. Available

from: http://www.who.int/news-room/factsheets/detail/cancer. [Accessed: 30Sep-2018].

3. Kushi LH, Doyle C, McCullough M, et al. American Cancer Society Guidelines on nutrition and physical activity for cancer prevention: reducing the risk of cancer with healthy food choices and physical activity. CA Cancer J Clin 2012;62:30-67.

4. Edwards BK, Ward E, Kohler BA, et al. Annual report to the nation on the status of cancer, 1975-2006, featuring colorectal cancer trends and impact of interventions (risk factors, screening, and treatment) to reduce future rates. Cancer 2010;116:544-73.

5. Colditz GA, Baer HJ, Tamimi RM. Breast cancer. In: D Schottenfeld, JF Fraumeni, eds. Cancer Epidemiology and Prevention. 3rd ed. New York: Oxford University Press; 2006:995-1012.

6. Colditz GA, Sellers TA, Trapido E. Epidemiology-identifying the causes and preventability of cancer? Nat Rev Cancer 2006;6:75-83.

7. Global Initiative for Cancer Registry Development (GICR) Website. Available: http://gicr.iarc.fr/en/. [Accessed: 30-Sep-2018].

8. Ferlay J, Shin HR, Bray F, et al. Estimates of worldwide burden of cancer in 2008: GLOBOCAN 2008. Int J Cancer 2010;127:2893-917.

9. Fatunmbi M, Saunders A, Chugani B, et al. Cancer Registration in Resourcelimited Environments-Experience in Lagos, Nigeria. J Surg Res 2019;235: 167-70.

10. Jedy-Agba E, Curado MP, Ogunbiyi O, et al. Cancer incidence in Nigeria: a report from population-based cancer registries. Cancer Epidemiol 2012;36: e271-8.

11. Parkin DM, Bray F, Ferlay J, Jemal A. Cancer in Africa 2012. Cancer Epidemiol Prevent Biomark 2014;23: 953-66.

12. USAID African Strategies for Health. Health Financing Profile: Nigeria. Feb. 2016. Available from: http://www.africanstrategies4health.org/uploads/1/3/5/ 3/13538666/country_profile_nigeria_us letter_final.pdf

13. World ${ }^{-}$Health Organization Global Health Expenditure database. Current health expenditure ( $\%$ of GDP) (apps.who.int/nha/database . 2020

14. Bein, Murad A, et al. Healthcare spending and health outcomes: evidence from selected East African countries. Afr Health Sci 2017;17:247-54.

15. Makuta I, O'Hare B. Quality of governance, public spending on health and health status in Sub Saharan Africa: a panel data regression analysis. BMC Public Health 2015;15:932.

16. Sango C, Yinka E, Bein MA. The Impact of Healthcare spending on Life Expectancy: Evidence from Selected West African Countries. Afr J Reprod Health 2018;22:64-71.

17. Tandon A, Murray CJL, Lauer JA, Evans DB. Measuring Overall Health System Performance for 191 Countries. GPE Discussion Paper Series: No. 30. EIP/GPE/EQC. World Health Organization (2000). Available from: https://www.who.int/healthinfo/paper3 $0 . p d f$.

18. PharmAccess:https://www.pharmaccess.org/wp-content/uploads/2018/ $01 /$ The-healthcare-system-inNigeria.pdf (2016).

19. World Health Organization Global Health Expenditure database. Out-ofpocket expenditure $(\%$ of current health expenditure) (apps.who.int/nha/database). 2020.

20. Ramsden V, Eguzo K, Olatunbosun O, et al. Review of cancer control policy in Nigeria and comparison with selected African countries implications for future policy making. IBOM Med J 2019;13:1-11.

21. Nwogu CE, Mahoney M, Okoye I, et al. Role of Private Enterprise in Cancer Control in Low to Middle Income Countries. J Cancer Epidemiol 2016:7121527.

22. Nigeria National System of Cancer Registries (NSCR). Federal Ministry of Health. Available from: https://nigeriancancerregistries.net/contact-details-ofnigerian-cancer-registries-personnel/

23. Nigeria. National Cancer Control Plan (NCCP) 2018-2022. Available from: https://www.iccp-portal.org/ system/files/plans/NCCP_Final $\% 20 \% 5$ B1\%5D.pdf

24. Mathew A. Global Survey of Clinical Oncology Workforce. J Glob Oncol 2018;4:1-12.

25. Adepoju P. For many in Nigeria, cancer care remains out of reach. DEVEX. Available from:

https://www.devex.com/news/for-many-in- nigeria-cancer-care-remains-out-ofreach-95669

26. Stanford Medicine. Collaboration aims to improve cancer care in Nigeria. April 2018. Available from: https://med.stanford.edu/news/allnews/2018/04/collaboration-aims-toimprove-cancer-care-in-nigeria.html

27. Sylla BS, Wild CP. A million Africans a year dying from cancer by 2030: what can cancer research and control offer to the continent? Int $\mathrm{J}$ Cancer 2012;130:245-50.

28. Vanderpuye V, Hammad N, Martei Y, et al. Cancer care workforce in Africa: perspectives from a global survey. Infect Agent Cancer 2019;14:11.

29. Pruitt L, Mumuni T, Raikhel E, et al. Social barriers to diagnosis and treatment of breast cancer in patients presenting at a teaching hospital in Ibadan, Nigeria. Global Public Health 2015;10:331-44.

30. Asuzu CC, Akin-Odanye EO, Asuzu $\mathrm{MC}$, et al. A socio-cultural study of traditional healers role in African health care. Infect Agents Cancer 2019;14:15.

31. Ibrahim NA, Odusanya OO. Knowledge of risk factors, beliefs and practices of female healthcare professionals towards breast cancer in a tertiary institution in Lagos, Nigeria. BMC Cancer 2009;9:76.

32. National Cancer Institute. (2019). Age. Available at: https://www.cancer.gov/ about-cancer/causes-prevention /risk/age

33. White MC, Holman DM, Boehm JE, et al. Age and cancer risk: a potentially modifiable relationship. Am J Prev Med 2014;46:S7-S15.

34. WHO. Nigeria Key Indicators. http://apps.who.int/gho/data/node.cco.k i-NGA?lang=en [Accessed 8 Mar. 2019].

35. Awodele O, Adeyomoye AA, Awodele DF. Cancer distribution pattern in south-western Nigeria. Tanz J Health Res 2011;13:106-8.

36. Cancer in Nigeria 2009-2013. Abuja, Nigeria: Nigeria National System of Cancer Registries, 2016.

37. Hunt K, Adamson J, Hewitt C, Nazareth I. Do women consult more than men? A review of gender and consultation for back pain and headache. J Health Serv Res Policy 2011;16:108-17.

38. Hall MT, Simms KT, Lew JB, et al. The Projected Time Frame until Cervical Cancer Elimination in Australia: A Modelling Study. Lancet Public Health 2019;4:e19-27.

39. Oladeji A, Atalabi O, Jimoh M, et al. Delay in Presentation of Cancer 
Patients for Diagnosis and Management: An Institutional Report. Internet J Oncol 2017;13:1.

40. Ezeome ER. Delays in presentation and treatment of breast cancer in Enugu, Nigeria. Nig J Clin Pract 2010;13:3116.

41. Koo MM, Swann R, McPhail S, et al. Presenting Symptoms of Cancer and Stage at Diagnosis: Evidence from a Cross-Sectional, Population-Based Study. Lancet Oncol 2020;21:73-9.

42. Ishola F, Omole O. A vision for improved cancer screening in Nigeria. Lancet Glob Health 2016;4:e359-60.

43. Sarki A, Roni BL. This disease is not for hospital: myths and misconceptions about cancers in Northern Nigeria. J Glob Health Rep 2019;3.

44. Ololade KO, Alabi A, Fadipe B, Adegboyega B. The 'Evil Arrow' Myths and Misconceptions of Cancer at Lagos University Teaching Hospital, Nigeria. South Afr J Oncol 2019;3:49.

45. Robertson C. A Survey of the Nigerian
Middle Class. 26 Sept. 2011. Available from: http://www.fastestbillion. com/res/Research/Survey_Nigerian_mi ddle_class-260911.pdf

46. Nigeria National Minimum Wage. 2018-2020 Data. 2021-2022 Forecast | Historical. tradingeconomics.com, https://tradingeconomics.com/nigeria/minimum-wages. Accessed 25 June 2020.

47. RFI. Forty percent of Nigerians live below poverty line: statistics office. April 2020. https://sundiatapost.com/40-of-nigerians-live-in-poverty-nbs/

48. Leng J, Ntekim AI, Ibraheem A, et al. Infrastructural Challenges Lead to Delay of Curative Radiotherapy in Nigeria. JCO Global Oncol 2020;6:26976.

49. Abubakar M, Basiru S, Oluyemi J, et al. Medical Tourism in Nigeria: Challenges and Remedies to Health Care System Development. Int J Dev Manag Rev 2018;13:223-38.
50. healthnews.ng. Nigeria is buying radiotherapy machines but most patients cannot afford cancer.drugswww.healthnews.ng/nigeria-isbuying-radiotherapy-machines-butmost-patients-cannot-afford-cancerdrugs/ [Accessed 25 Jun. 2020].

51. Asuzu CC, Akin-Odanye EO, Asuzu $\mathrm{MC}$, et al. A socio-cultural study of traditional healers role in African health care. Infect Agents Cancer 2019;14:15.

52. Asuzu CC, Elumelu-Kupoluyi T, Asuzu $\mathrm{MC}$, et al. A pilot study of cancer patients' use of traditional healers in the Radiotherapy Department, University College Hospital, Ibadan, Nigeria. Psycho-Oncol 2017;26:369-76.

53. Ezeome ER, Anarado AN. Use of complementary and alternative medicine by cancer patients at the University of Nigeria Teaching Hospital, Enugu, Nigeria. BMC Complement Altern Med 2007;7:28. 